\title{
Long non-coding RNA CCAT1 promotes colorectal cancer cell migration, invasiveness and viability by upregulating VEGF via negative modulation of microRNA-218
}

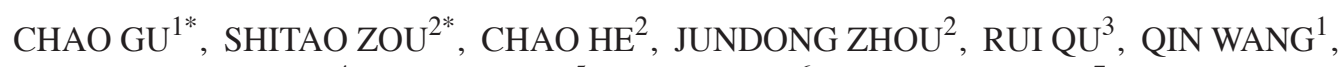 \\ $\mathrm{JIE} \mathrm{QI}^{4}$, MING ZHOU ${ }^{5}$, SHUAI YAN ${ }^{6}$ and ZHENYU YE ${ }^{7}$
}

\begin{abstract}
${ }^{1}$ Gastrointestinal Surgery Department; ${ }^{2}$ Suzhou Cancer Center Core Laboratory; ${ }^{3}$ Clinical Laboratory; and
${ }^{4}$ Thyroid and Breast Surgery Department, The Affiliated Suzhou Hospital of Nanjing Medical University, Suzhou, Jiangsu 215000; ${ }^{5}$ General Surgery, The Second Clinical Medical College, Yangtze University, Jingzhou Central Hospital, Jingzhou, Hubei 434020; ${ }^{6}$ Colorectal Surgery, Suzhou TCM Hospital Affiliated to Nanjing University of Chinese Medicine, Suzhou, Jiangsu 215009; ${ }^{7}$ Department of Hepatobiliary Surgery, The Second Affiliated Hospital of Soochow University, Suzhou, Jiangsu 215000, P.R. China
\end{abstract}

Received March 22, 2019; Accepted January 28, 2020

DOI: $10.3892 /$ etm.2020.8518

\begin{abstract}
Increasing evidence has demonstrated that long non-coding (lnc) RNA is aberrantly expressed in numerous types of cancer. Colorectal cancer is a common malignancy; however, the role and mechanism underlying the influence of 1ncRNA-colon cancer associated transcript 1 (CCAT1) in colorectal cancer is yet to be elucidated. The present study revealed that CCAT1 is highly expressed in colorectal cancer tissues. Bioinformatics analysis and a dual-luciferase reporter gene assay indicated that CCAT1 and microRNA (miR)-218 had complementary binding sites. Furthermore, reverse transcription-quantitative PCR revealed that miR-218 was downregulated in colorectal cancer tissues compared with paired adjacent healthy tissues. To investigate the biological effects of CCAT1 on colorectal cancer cells, MTT and Transwell assays were performed. The results revealed that when compared with the control group, CCAT1-short hairpin (sh)RNA significantly inhibited colorectal cancer cell (SW480) viability and decreased migration and invasiveness. In addition, CCAT1-shRNA significantly reduced vascular
\end{abstract}

Correspondence to: Dr Shuai Yan, Colorectal Surgery, Suzhou TCM Hospital Affiliated to Nanjing University of Chinese Medicine, 18 Yangsu Road, Suzhou, Jiangsu 215009, P.R. China

E-mail:plmokn74123@163.com

Dr Zhenyu Ye, Department of Hepatobiliary Surgery, The Second Affiliated Hospital of Soochow University, 1055 Sanxiang Road, Suzhou, Jiangsu 215000, P.R. China

E-mail: yezhenyu020319@163.com

\section{*Contributed equally}

Key words: long non-coding colon cancer associated transcript 1, microRNA-218, colorectal cancer, vascular endothelial growth factor endothelial growth factor (VEGF) expression in SW480 cells; however, these effects were partially rescued by an miR-218 inhibitor. Furthermore, it was revealed that the CCAT1-plasmid significantly promoted the viability of SW480 cells, increased cell migration and invasiveness, and significantly increased VEGF expression. However, these effects were also partially rescued by with a miR-218 mimic. Taken together, the present results identified that the CCAT1/miR-218 axis serves a key role in the regulation of colorectal cancer progression, which may be used as potential therapeutic target for the treatment of colorectal cancer.

\section{Introduction}

Colorectal cancer (CRC) is one of the most common malignant cancers worldwide, and is the third leading cause of cancer-associated mortality in developed countries (1). A characteristic feature of $\mathrm{CRC}$ is the rapid proliferation of cells in the colon and rectum. In China, it was reported that the number of novel CRC cases was 376,300 and the number of mortalities was 191,000 in 2015 (2). In 2017 the incidence of CRC in the general population worldwide was $5 \%$ and the 5-year survival rate was between 40-60\% (3). Despite recent advances in the treatment of $\mathrm{CRC}$, including surgical resection, radiation therapy and chemotherapy, the survival rate of patients is still low (4-6). Therefore, the development of novel therapeutic options may confer survival benefits on patients with CRC.

Previous studies have revealed (via integrated genomic and transcriptome sequencing results) that $>90 \%$ of DNA sequences are actively transcribed, of which $98 \%$ are transcribed into various non-coding RNAs, including microRNAs (miRNAs or miRs) and long non-coding (lnc)RNAs $(7,8)$. IncRNAs are $>200$ nucleotides in length and do not code for proteins (9). lncRNAs regulate gene expression at different levels and serve a crucial role in multiple biological processes $(10,11)$. It has been reported that IncRNAs are aberrantly expressed in mammalian and plant cells $(12,13)$. There is increasing 
evidence that lncRNAs may serve as novel biomarkers for the diagnosis and prognosis of numerous types of cancer, including hepatocellular carcinoma, gastric cancer, non-small cell lung cancer and pancreatic cancer (14-19).

Colon cancer associated transcript 1 (CCAT1) is a novel IncRNA that was identified via representative differential analysis, cDNA cloning and the rapid amplification of cDNA ends. The well-characterized cancer gene, c-Myc, is located in the chromosomal 8q24 region, which is comprised of multiple genes associated with CRC $(20,21)$. Previous studies have revealed that CCAT1 is activated and upregulated by c-Myc at the transcriptional level, which results in the promotion of tumorigenesis, progression, invasion and metastasis (22-24). miR-218 is a tumor-suppressive miRNA that suppresses the proliferation of glioma (25) and mesenchymal stem cells (26). Additionally, miR-218 inhibits synovial osteogenic differentiation and inhibits the angiogenesis of prostate cancer (27). However, the role of CCAT1 and miR-218 in CRC is yet to be fully elucidated. Therefore, the present study aimed to investigate the expression and role of CCAT-1 and miR-218 in CRC.

\section{Materials and methods}

Tissue samples. A total of $30 \mathrm{CRC}$ specimens and paired normal adjacent cancer tissues ( $>2 \mathrm{~cm}$ from the tumor border) were collected during colorectal resection from 30 patients with CRC (21 males, 9 females; age, 26-72 years old; median age, 51) during gastrointestinal surgery in the Affiliated Suzhou Hospital of Nanjing Medical University (Suzhou, China) between January 2016 and January 2017. The exclusion criteria were: i) Patients that had received pre-operative chemotherapy or radiotherapy treatments; ii) patients that had other malignancies or infectious disease; iii) patients with hereditary CRC syndromes. The present study was approved by the Ethics Committee of the aforementioned Hospital and all patients provided written informed consent.

Cell culture and transfection. Human CRC cells (SW480; ATCC) were cultured with RPMI-1640 medium (Gibco; Thermo Fisher Scientific, Inc.) containing $10 \%$ fetal bovine serum (FBS; Gibco; Thermo Fisher Scientific, Inc.) at $37^{\circ} \mathrm{C}$ in a $5 \% \mathrm{CO}_{2}$ incubator. SW480 cells were subsequently transfected with $1 \mu \mathrm{g}$ short hairpin (sh)RNA (CCAT1-shRNA; Guangzhou RiboBio Co., Ltd.), $1 \mu \mathrm{g}$ negative control shRNA (control-shRNA; Guangzhou RiboBio Co., Ltd.), 100 nM miR-218 inhibitors (5'-ACAUGGUUAGAUCAA GCACAA-3'; Guangzhou RiboBio Co., Ltd.), 100 nM miR-218 inhibitor controls (inhibitor controls; 5'-UCACAA CCUCCUAGAAAGAGUAGA-3'; Guangzhou RiboBio Co., Ltd.), $1 \mu \mathrm{g}$ CCAT1-shRNA + 100 nM miR-218 inhibitors, $1 \mu \mathrm{g}$ pcDNA3.1-CCAT1 (CCAT1-plasmids; Shanghai GenePharma Co., Ltd.), $1 \mu \mathrm{g}$ control pcDNA3.1 plasmids (control-plasmids; Shanghai GenePharma Co., Ltd.), $100 \mathrm{nM}$ miR-218-mimics (5'-TTGTGCTTGATCTAACCATGT-3'; Shanghai GenePharma Co., Ltd.), 100 nM miR-218 mimics negative controls (mimic-controls: 5'-TTCTCCGAACGT GTCACGTTTC-3'; Shanghai GenePharma Co., Ltd.) or $1 \mu \mathrm{g}$ CCAT1-plasmid + $100 \mathrm{nM}$ miR-218 mimics for $48 \mathrm{~h}$ using Lipofectamine ${ }^{\circledR} 2000$ reagent (Invitrogen; Thermo Fisher Scientific, Inc.), according to the manufacturer's protocol.
Transfection efficiency was determined $48 \mathrm{~h}$ post-transfection via reverse transcription-quantitative (RT-q) PCR. Untreated cells were used as controls.

MTT assay. SW480 cell viability was determined using an MTT assay. Cells were seeded in 96-well plates at a density of $5 \times 10^{3}$ cells/well. After incubation at $37^{\circ} \mathrm{C}$ for $48 \mathrm{~h}, 20 \mu \mathrm{l} \mathrm{MTT}$ reagent (Sigma-Aldrich; Merck $\mathrm{KGaA}$ ) was added into each well and incubated for a further $4 \mathrm{~h}$ at $37^{\circ} \mathrm{C}$. Subsequently, $150 \mu \mathrm{l}$ dimethyl sulfoxide (Sigma-Aldrich; Merck KGaA) was added into each well and the suspension was agitated for $15 \mathrm{~min}$. The optical density was measured at $490 \mathrm{~nm}$ using a micro-plate reader.

Transwell assay. To investigate migration, SW480 cells ( $2 \times 10^{4}$ cells per well) re-suspended in RPMI-1640 medium were plated in the upper, uncoated Transwell chambers (pore size, $8 \mu \mathrm{m}$; Costar; Corning Inc.). RPMI-1640 medium with $10 \%$ FBS was plated in the lower chamber to induce cell migration. After $24 \mathrm{~h}$, the migratory cells in the lower chamber were fixed with $4 \%$ paraformaldehyde at room temperature for $30 \mathrm{~min}$. Then, cells were washed in triplicate with PBS and stained using $0.1 \%$ crystal violet for $20 \mathrm{~min}$ at room temperature. The number of migrated cells were counted under a light microscope at a magnification of x200 using five random fields of view. For cell invasion assay, the upper chamber was coated with $200 \mathrm{mg} / \mathrm{ml}$ of BD Matrigel ${ }^{\mathrm{TM}}$ Matrix (BD Biosciences) at $37^{\circ} \mathrm{C}$ for $30 \mathrm{~min}$. The same protocol was followed as described above for the migration assay.

$R T-q P C R$. Tissue samples and SW480 cells were treated with TRIzol $^{\circledR}$ (Invitrogen; Thermo Fisher Scientific, Inc.) and total RNA was extracted according to the manufacturer's protocol. cDNA was then synthesized using the miScript Reverse Transcription kit (Qiagen $\mathrm{GmbH}$ ) according to the manufacturer's protocol. The temperature protocol for this step was as follows: $70^{\circ} \mathrm{C}$ for $5 \mathrm{~min}, 37^{\circ} \mathrm{C}$ for $5 \mathrm{~min}$ and $42^{\circ} \mathrm{C}$ for $1 \mathrm{~h}$. qPCR was then performed using QuantiFast SYBR-Green PCR kit (Qiagen $\mathrm{GmbH}$ ) in accordance with the manufacturer's protocol. The thermocycling conditions were as follows: $95^{\circ} \mathrm{C}$ for $3 \mathrm{~min}$, followed by 40 cycles of $95^{\circ} \mathrm{C}$ for $30 \mathrm{sec}, 56^{\circ} \mathrm{C}$ for $30 \mathrm{sec}$ and $72^{\circ} \mathrm{C}$ for $30 \mathrm{sec}$. GAPDH or U6 were used as internal controls for normalization. The primer sequences were as follows: CCAT1 forward, 5'-AGAAACACTATCACC TACGC-3' and reverse, 5'-CTTAACAGGGCATTGCTAATC T-3'; GAPDH forward, 5'-TGTTGCCATCAATGACCCCTT-3' and reverse, 5'-CTCCACGACGTACTCAGCG-3'; U6 forward, 5'-GCTTCGGCAGCACATATACTAAAAT-3' and reverse 5'-CGCTTCACGAATTTGCGTGTCAT-3'; miR-218 forward, 5'-GTTGTGCTTGATCTAACCATGT-3' and reverse, 5'-CTC GCTTCGGCAGCACA-3'; vascular endothelial growth factor (VEGF) forward, 5'-GAGCCTTGCCTTGCTGCTCTAC-3' and reverse, 5'-CACCAGGGTCTCGATTGGATG-3'. Relative gene expression was calculated using the $2^{-\Delta \Delta \mathrm{Cq}}$ method (28).

Western blotting. Total protein from SW480 cells was extracted using radioimmunoprecipitation assay (RIPA) buffer (Beyotime Institute of Biotechnology) with phenylmethylsulfonyl fluoride (PMSF; Beyotime Institute of Biotechnology). The protein concentration was subsequently determined 


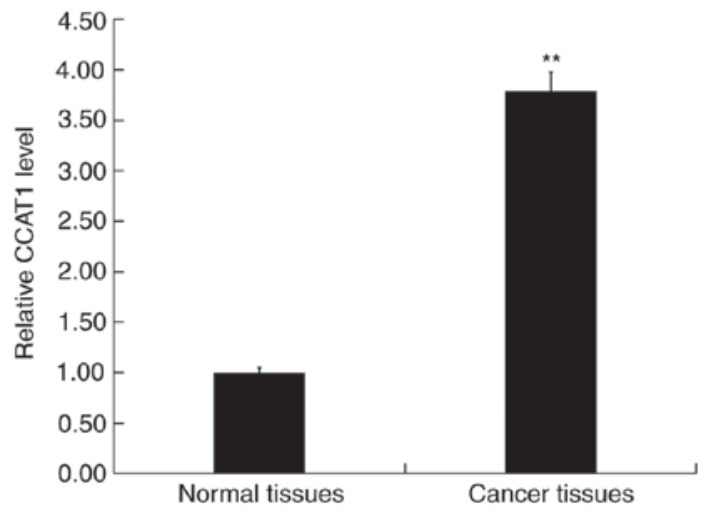

Figure 1. CCAT1 is highly expressed in CRC tissues. Reverse transcription-quantitative PCR was performed to detect the expression of CCAT1 in $\mathrm{CRC}$ tissue (cancer tissues) and adjacent normal tissue (normal tissues). Data were presented as the mean $\pm \mathrm{SD} .{ }^{* *} \mathrm{P}<0.01$ vs. normal tissues. CCAT1, colon cancer associated transcript 1; CRC, colorectal cancer.

using a bicinchoninic acid assay kit (Beyotime Institute of Biotechnology). A total of $30 \mu \mathrm{g}$ of protein was loaded per lane and separated via $12 \%$ SDS-PAGE. Samples were then transferred to PVDF membranes (Bio-Rad Laboratories, Inc.), which were subsequently were blocked using $5 \%$ skimmed milk in TBS containing 0.1\% Tween (Beyotime Institute of Biotechnology) at room temperature for $1.5 \mathrm{~h}$. Membranes were incubated with the following primary antibodies: VEGF (1:1,000; cat no. ab53465; Abcam) and $\beta$-actin (1:1,000; cat no. 4970; Cell Signaling Technology, Inc.) at $4^{\circ} \mathrm{C}$ overnight. Subsequently, the membranes were incubated with horseradish peroxidase-conjugated anti-rabbit IgG secondary antibodies (1:2,000; cat no. 7074 ; Cell Signaling Technology, Inc.) at room temperature for $1 \mathrm{~h}$. Protein bands were visualized using an enhanced chemiluminescence assay (EMD Millipore). $\beta$-actin served as the loading control for normalization.

Dual-luciferase reporter assay. Starbase version 3.0 (http://starbase.sysu.edu.cn/) was used to identify associations between CCAT1 and miR-218. The results indicated that there were complementary binding sites between miR-218 and CCAT1. The fragment of CCAT1 containing the target sequence of miR-218 was amplified via RT-qPCR (as previously described) and then inserted into a pmirGLO vector (Promega Corporation) to form the wild-type CCAT1 reporter vector (CCAT1-WT). An additional expression vector was also constructed by inserting a mutated binding site and was termed CCAT1-mutated-type (CCAT1-MUT). SW480 cells were seeded into 24 -well plates at a density of $5 \times 10^{4}$ cells per well. When the confluency reached $\sim 80 \%$, SW480 cells were co-transfected with CCAT1-WT or CCAT1-MUT and miR-218 mimics or the negative control at $37^{\circ} \mathrm{C}$ for $48 \mathrm{~h}$ using Lipofectamine $2000^{\circledR}$ (Invitrogen; Thermo Fisher Scientific, Inc.), in accordance with the manufacturer's protocol. The relative luciferase activity was then determined using a Dual-Luciferase Reporter assay system (Promega Corporation) according to the manufacturer's protocol. Luciferase activity was normalized to the activity of Renilla.

Statistical analysis. Experiments were repeated three times and data are presented as the mean $\pm \mathrm{SD}$. Statistical analyses
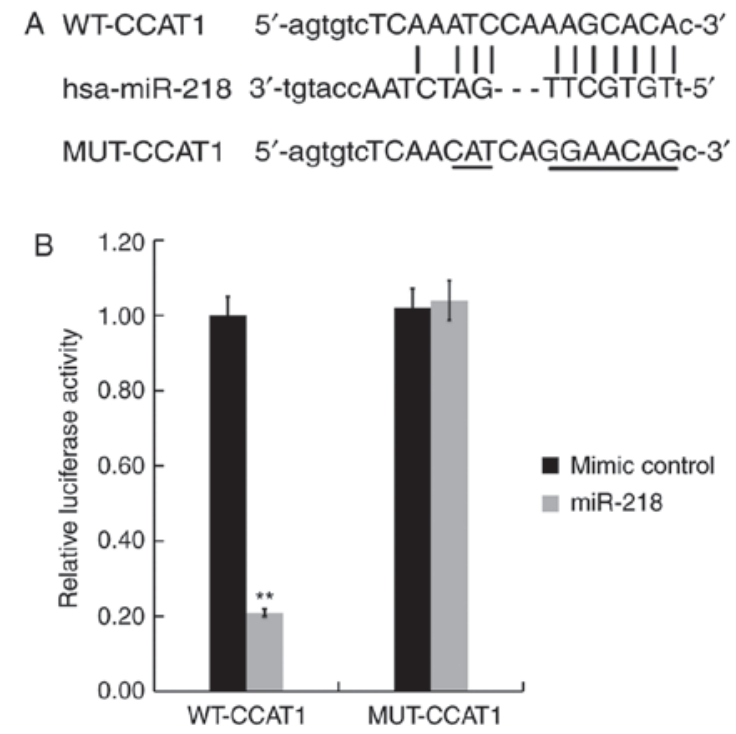

Figure 2. CCAT1 may bind to miR-218. (A) Potential binding sites of CCAT1 and miR-218. (B) A Dual-luciferase reporter gene assay was performed to confirm the binding sites between CCAT1 and miR-218. Data were presented as the mean \pm standard deviation. ${ }^{* *} \mathrm{P}<0.01$ vs. negative control. miR, microRNA; CCAT1, colon cancer associated transcript 1; WT, wild-type; MUT, mutant.

were performed using SPSS version 18.0 software (SPSS, Inc.). Significant differences between groups was calculated using a paired Student's t-test or one-way ANOVA followed by Tukey's post-hoc test. $\mathrm{P}<0.05$ was considered to indicate a statistically significant difference.

\section{Results}

Expression of CCAT1 in patients with CRC. RT-qPCR was performed to detect the expression of CCAT1 in CRC and adjacent normal tissues. The results revealed that when compared with adjacent normal tissues, CCAT1 expression was significantly upregulated in CRC (Fig. 1).

$C C A T 1$ directly binds to miR-218. To verify the association between CCAT1 and miR-218, bioinformatics analysis was performed using Starbase version 3.0 to identify potential binding sites between CCAT1 and miR-218. The results indicated that a complementary binding site existed between CCAT1 and miR-218 (Fig. 2A). A dual-luciferase reporter assay was then performed to validate the predicted result. SW480 cells were co-transfected with a luciferase plasmid containing the CCAT1 sequence (CCAT1-WT or CCAT1-MUT) and the miR-218 mimic or the negative control. The results demonstrated that the miR-218 mimic significantly inhibited the luciferase activity of CCAT1-WT, while the miR-218 mimic did not exert an inhibitory effect on CCAT1-MUT (Fig. 2B). Taken together, the results indicated that CCAT1 may bind directly to miR-218.

Expression of miR-218 in patients with CRC. RT-qPCR was performed to detect the expression of miR-218 in $30 \mathrm{CRC}$ and paired adjacent normal tissues. The results indicated that the expression of miR-218 was significantly downregulated in CRC tissues compared with normal tissues (Fig. 3). 


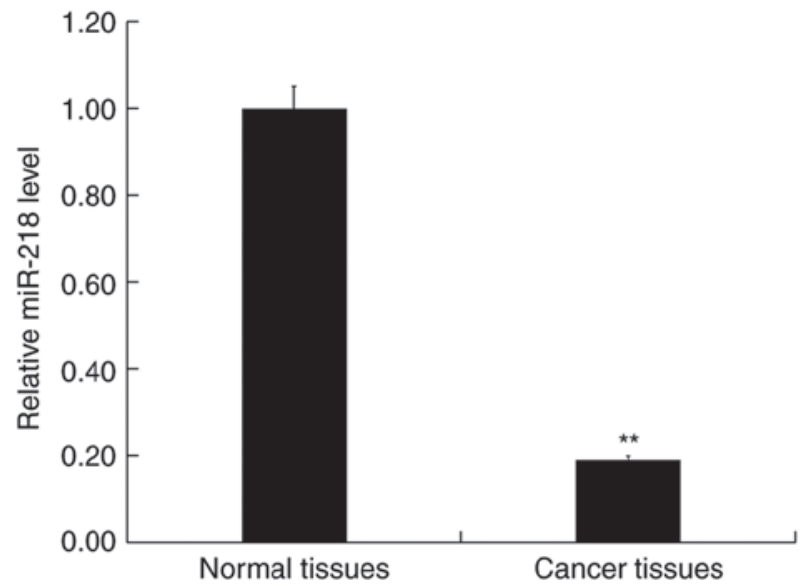

Figure 3. miR-218 is downregulated in patients with CRC. Reverse transcription-quantitative PCR was performed to detect the expression of miR-218 in CRC specimens (cancer tissues) and adjacent normal tissues (normal tissues). Data were presented as the mean $\pm \mathrm{SD}$. ${ }^{* *} \mathrm{P}<0.01$ vs. normal tissues. CRC, colorectal cancer; miR, microRNA.

Downregulation of CCAT1 is associated with an increase of miR-218 expression in SW480 cells. SW480 cells were transfected with either CCAT1-shRNA, control-shRNA, miR-218 inhibitors, inhibitor controls or CCAT1-shRNA + miR-218 inhibitor for $48 \mathrm{~h}$, respectively. Subsequently, RT-qPCR was performed to detect transfection efficiency. When compared with the control group, CCAT1-shRNA significantly reduced the expression of CCAT1 in SW480 cells (Fig. 4A) whilst the miR-218 inhibitor significantly decreased the expression of miR-218 (Fig. 4B). Furthermore, the results of the present study indicated that CCAT1-shRNA significantly increased the expression of miR-218 in SW480 cells, which was partially reversed following treatment with the miR-218 inhibitor (Fig. 4C).

Effect of CCAT1 knockdown on SW480 cell viability, migration and invasion. To investigate the influence of CCAT1 on the biological activity of SW480 cells, cells were transfected with CCAT1-shRNA, control-shRNA or CCAT1-shRNA + miR-218 inhibitor for $48 \mathrm{~h}$. The results of the MTT assay revealed that, when compared with the control group, CCAT1-shRNA significantly inhibited the viability of SW480 cells (Fig. 5A). Furthermore, the results of the Transwell assay indicated that CCAT1-shRNA significantly suppressed SW480 cell migration and invasion (Fig. 5B-E). Western blotting demonstrated that CCAT1-shRNA markedly reduced VEGF expression in SW480 cells at the protein level (Fig. 5F). Additionally, CCAT1-shRNA significantly reduced the mRNA expression of VEGF in SW480 cells (Fig. 5G). The aforementioned effects occurring after CCAT1-shRNA treatment were all partially reversed by co-transfection with a miR-218-inhibitor. The current results indicated that CCAT1-shRNA inhibited CRC cell viability, migration and invasion by downregulating VEGF expression via miR-218 modulation.

CCAT1 upregulation inhibits miR-218 expression in SW480 cells. To further investigate the role of CCAT1 and miR-218 in CRC, SW480 cells were transfected with CCAT1-plasmids, control-plasmids, miR-218-mimics, mimic controls or CCAT1-plasmid + miR-218 mimics for $48 \mathrm{~h}$. Subsequently, an
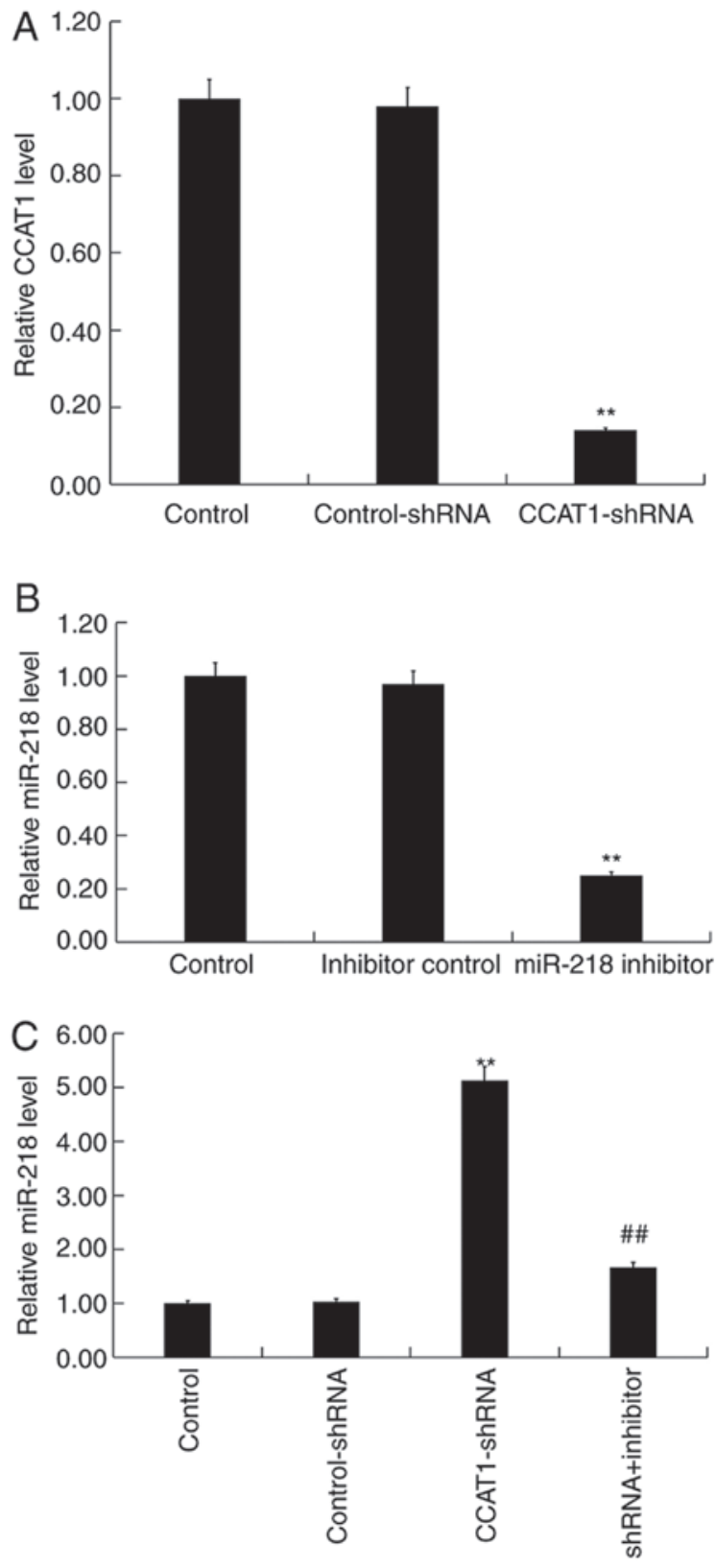

Figure 4. CCAT1 knockdown enhances miR-218 expression in SW480 cells. (A) Expression of CCAT1 was detected via RT-qPCR following SW480 cell transfection with CCAT1-shRNA or control-shRNA. (B) Expression of miR-218 was detected by RT-qPCR following transfection with miR-218 inhibitors or inhibitor control. (C) Expression of miR-218 was detected via RT-qPCR following SW480 cell transfection with CCAT1-shRNA, control-shRNA, or CCAT1-shRNA + miR-218 inhibitor. Data were presented as the mean $\pm \mathrm{SD} .{ }^{* *} \mathrm{P}<0.01$ vs. control; ${ }^{\# \#} \mathrm{P}<0.01$ vs. CCAT1-shRNA. CCAT1, colon cancer associated transcript 1 ; miR, microRNA; RT-qPCR, reverse transcription-quantitative PCR; shRNA, short hairpin RNA.

RT-qPCR assay was performed to detect transfection efficiency. The results revealed that the CCAT1-plasmid significantly increased the expression of CCAT1 in SW480 cells compared with the control group (Fig. 6A). Furthermore, the miR-218 mimic significantly increased the expression of miR-218 in SW480 cells compared with the control group (Fig. 6B). Treatment with the CCAT1-plasmid significantly reduced the expression of miR-218 in SW480 cells compared with the control group, which was partially rescued by co-transfection with the miR-218 mimic (Fig. 6C). 


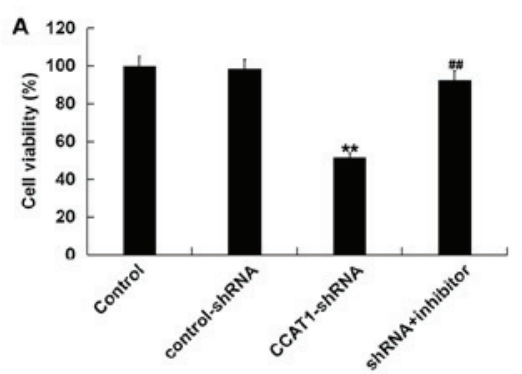

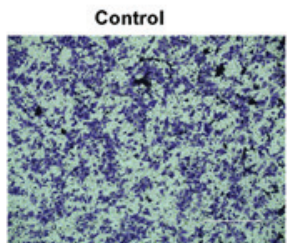

Control-shRNA

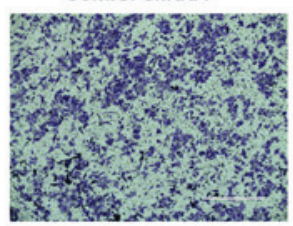

CCAT1-shRNA

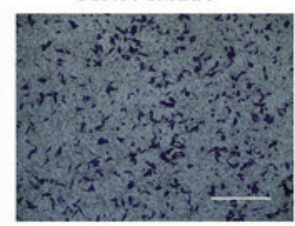

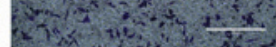
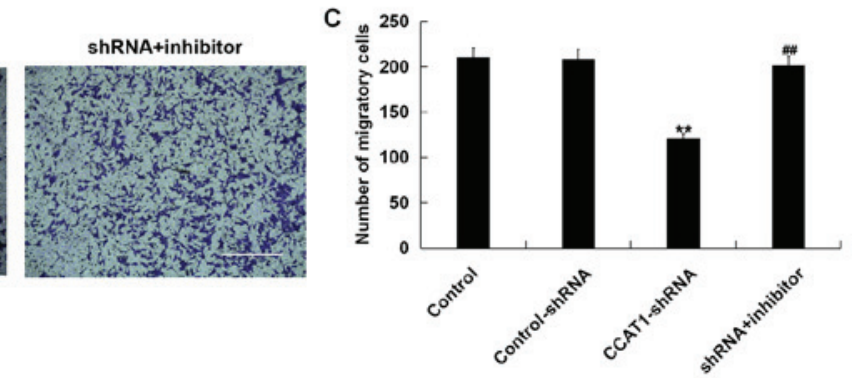

E

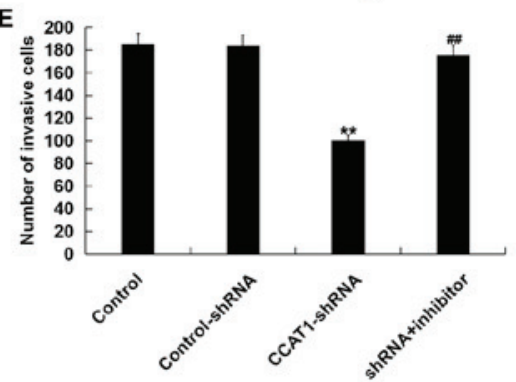

$\mathbf{F}$

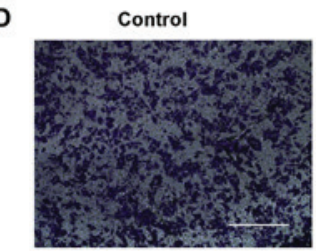

Control-shRNA

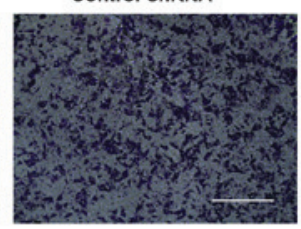

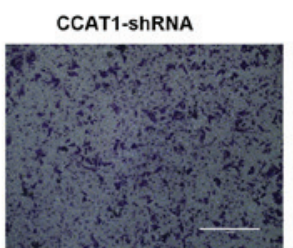
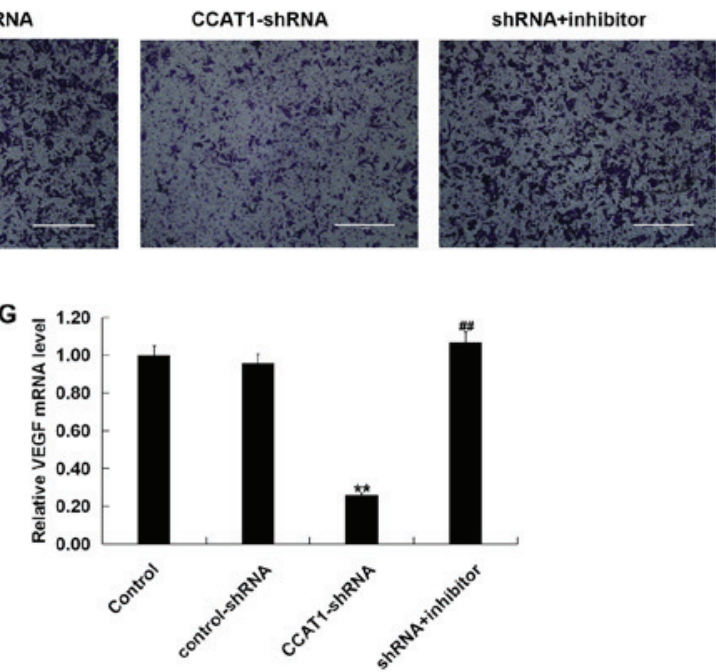

Figure 5. Knockdown of CCAT1 suppresses the viability, migration and invasiveness of SW480 cells. SW480 cells were transfected with CCAT1-shRNA, control-shRNA or CCAT1-shRNA+miR-218 inhibitor for 48 h. (A) Cell viability was detected using an MTT assay. Cell migration was subsequently determined using a Transwell assay. (B) Cell images and (C) the number of migratory cells are presented. Invasion was detected using a Transwell assay with Matrigel. Results are presented as (D) cell images and (E) the number of invasive cells. (F) Western blotting was performed to measure the protein expression of VEGF in SW480 cells transfected with CCAT1-shRNA, control-shRNA, or CCAT1-shRNA + miR-218 inhibitor. (G) Reverse transcription-quantitative PCR was used to detect the mRNA expression of VEGF in SW480 cells transfected with CCAT1-shRNA, control-shRNA or CCAT1-shRNA + miR-218 inhibitor. Data were presented as the mean $\pm \mathrm{SD} .{ }^{* *} \mathrm{P}<0.01$ vs. control; ${ }^{\# \#} \mathrm{P}<0.01$ vs. CCAT1-shRNA. Scale bars, $400 \mu \mathrm{m}$. CCAT1, colon cancer associated transcript 1; shRNA, short hairpin RNA; miR, microRNA; VEGF, vascular endothelial growth factor.

Increased expression of CCAT1 increases the viability, migration and invasiveness of SW480 cells. To investigate the effect of high CCAT1 levels on the viability, migration and invasiveness of SW480 cells, MTT and Transwell assays were performed. The MTT assay revealed that, compared with the control group, transfection with the CCAT1-plasmid significantly promoted the viability of SW480 cells (Fig. 7A). The Transwell assay indicated that transfection with a CCAT1-plasmid increased SW480 cell migration (Fig. 7B and C) and invasiveness (Fig. 7D and E). Furthermore, CCAT1-plasmid transfection increased VEGF expression in SW480 cells at the mRNA and protein levels (Fig. 7F and G). All effects were partially reversed following co-transfection with a miR-218 mimic. Taken together, the results indicated that the CCAT1-plasmid increased CRC cell viability, migration and invasiveness by promoting VEGF expression via miR-218 modulation.

\section{Discussion}

A number of studies have suggested that the lncRNA CCAT1 influences the progression of different types of cancer (20-24,29). The present study focused on the investigation of the role of 1ncRNA CCAT1 in CRC cells. Increasing evidence has revealed that IncRNAs serve a crucial role in the occurrence, progression and metastasis of various types of cancer (30-32). It has been reported that lncRNAs affect the tumorigenesis of CRC and are associated with clinical outcomes (33). Jiang et al (34) reported that IncRNA-gradually increased during hepatocarcinogenesis (GIHCG) was highly expressed in CRC tissues and cell lines, and that GIHCG deficiency suppressed cell migration and invasion. Shi et al (35) also indicated that lncRNA-ZNFX1 antisense RNA 1 (ZNFX1-AS1) was upregulated in CRC tissues and 

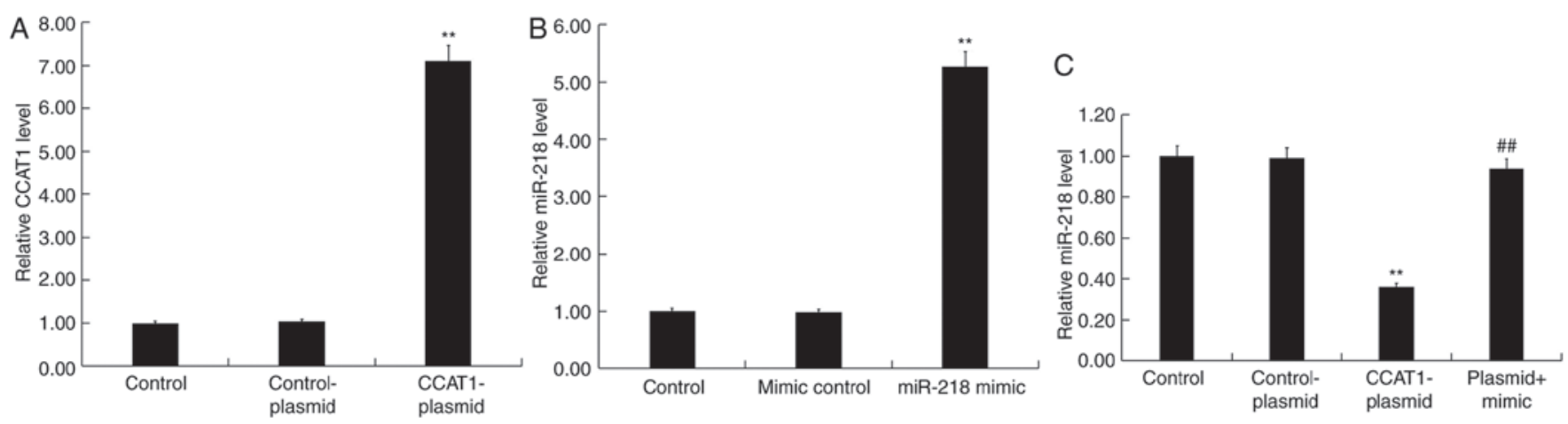

Figure 6. CCAT1 upregulation inhibits miR-218 expression in SW480 cells. Reverse transcription-quantitative PCR was performed to detect the expression of (A) CCAT1 following SW480 cell transfection with CCAT1-plasmids or control-plasmids. The expression of (B) miR-218 was assessed following SW480 cell transfection with miR-218 mimics or mimic controls. Levels of (C) miR-218 were determined following transfection with CCAT1-plasmids, control-plasmids or CCAT1-plasmid + miR-218 mimics. Data were presented as the mean $\pm \mathrm{SD} .{ }^{* *} \mathrm{P}<0.01$ vs. control-plasmid/mimic control; ${ }^{\# \#} \mathrm{P}<0.01$ vs. CCAT1-plasmid. CCAT1, colon cancer associated transcript $1 ;$ miR, microRNA.

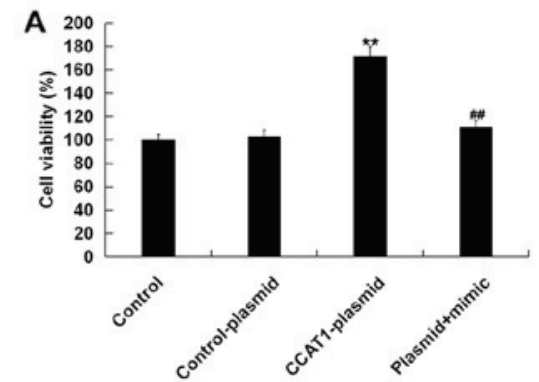

B

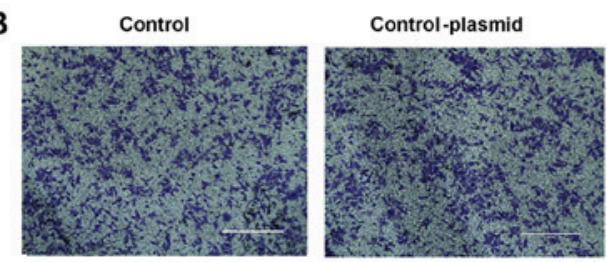

D

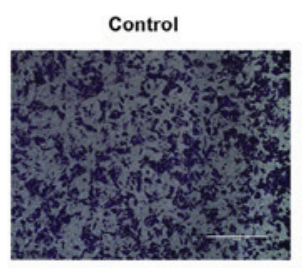

$\mathbf{F}$

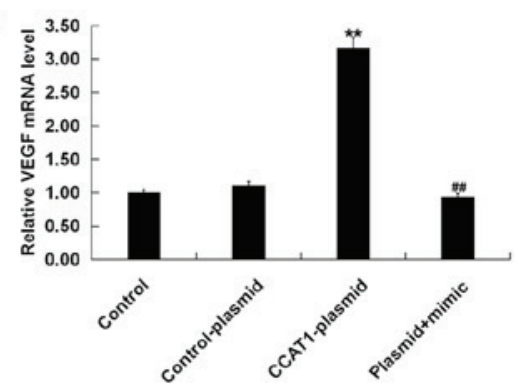

CCAT1-plasmid
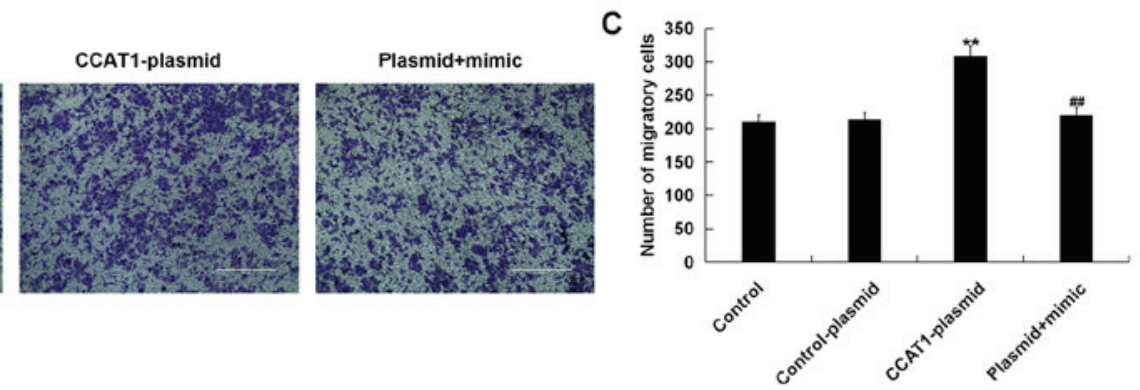

E

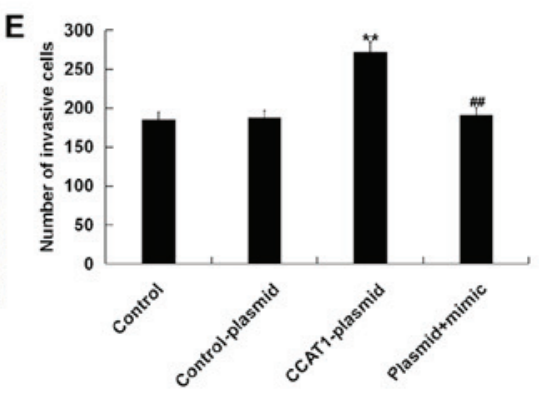

Figure 7. High expressions of CCAT1 promoted the viability, migration and invasion of SW480 cells. SW480 cells were transfected with CCAT1-plasmids, control-plasmids, or CCAT1-plasmid + miR-218 mimics for $48 \mathrm{~h}$. (A) An MTT assay was subsequently performed to detect cell proliferation and cell migration was determined using a Transwell assay. (B) cell images and (C) the number of migratory cells are presented. Invasion was detected using a Transwell assay with Matrigel. Similarly the results of are presented as (D) cell images and (E) quantified results. (F) Reverse transcription-quantitative PCR was performed to detect the relative expression of VEGF mRNA. (G) Western blotting was performed to detect the protein expression of VEGF. Data were presented as the mean $\pm \mathrm{SD} .{ }^{* *} \mathrm{P}<0.01$ vs. Control; ${ }^{\# \#} \mathrm{P}<0.01$ vs. CCAT1-plasmid. Scale bars, $400 \mu \mathrm{m}$. CCAT1, colon cancer associated transcript 1; miR, microRNA; RT-q, reverse transcription-quantitative; VEGF, vascular endothelial growth factor. 
cells, and ZNFX1-AS1 knockdown inhibited cell proliferation. In addition, previous studies have indicated that increased lncRNA-CCAT2 expression may serve as a potential biomarker for CRC diagnosis, and may also serve as an independent predictor of prognosis $(36,37)$. In the present study, CCAT1 expression was significantly upregulated in CRC tissue.

Bioinformatics analysis indicated that CCAT1 and miR-218 possess complementary binding sites. miR-218 has been identified as a tumor-suppressive factor in cancers, including cervical cancer, osteosarcoma and prostate cancer (38-40). Zhu et al (38) demonstrated that miR-218 is downregulated in cervical cancer and that miR-218 overexpression suppresses cervical cancer cell viability and induces cell apoptosis. Additionally, Xuan et al (39) reported that miR-218 was significantly downregulated in osteosarcoma cells and that treatment with miR-218 suppressed osteosarcoma formation in vivo. Zhang et al (40) demonstrated that lncRNA-prostate cancer antigen 3 (PCA3) regulated prostate cancer by sponging miR-218-5p and modulating high mobility group box 1 . In the present study, it was demonstrated that miR-218 was downregulated in CRC tissues.

VEGF, a potent angiogenic factor, serves a key role in the formation of new blood vessels in CRC (41). VEGF is upregulated in CRC tissues and anti-VEGF therapy has been applied to patients with metastatic CRC $(42,43)$. A previous study demonstrated that CCAT1 downregulation decreased thyroid cancer cell viability, proliferation, migration and invasion, and reduced VEGF expression (44). A further study revealed that miR-218 overexpression inhibited cell viability, promoted apoptosis and decreased the expression of VEGF in cervical cancer cells (40). The current study therefore hypothesized that CCAT1 inhibition may influence CRC cell viability and metastasis by downregulating VEGF expression via miR-218 sponging. Thus, the effect of CCAT1 on CRC cells and VEGF expression was investigated. The results revealed that CCAT1 was knocked down or overexpressed in CRC cells. The results further indicated that CCAT1 knockdown inhibited CRC cell viability, migration and invasion. Additionally, CCAT1 knockdown decreased the expression of VEGF in CRC cells; however, these inhibitory effects were partially reversed by co-transfection with a miR-218 inhibitor. CCAT1 overexpression exerted the opposite effect to CCAT1 knockdown in CRC cells. Taken together, the current results may provide novel insights into the roles and interactions of lnc-CCAT1 and miR-218 in CRC. However, this study only assessed the effects of CCAT1 on CRC cells in vitro, and in vivo studies should be performed to reveal the present results. This is a key limitation of this study.

In summary, CCAT1 influenced the expression of VEGF in CRC cells by negatively regulating miR-218. In addition, CCAT1 was revealed to mediate multiple biological functions underpinning the progression of CRC.

\section{Acknowledgements}

Not applicable.

\section{Funding}

The present study was supported by the Youth Science and Technology Project of Promoting Health through Science and
Education in Suzhou (grant no. KJXW2016029), the National Natural Science Foundation of China (grant no. 81804098) and the Jiangsu Province Youth Medical Talent Project (grant no. QNRC2016255).

\section{Availability of data and materials}

All data sets used and/or generated during the current study are available from the corresponding author on reasonable request.

\section{Authors' contributions}

CG and SZ contributed to study design, data collection, statistical analysis, data interpretation and manuscript preparation. $\mathrm{CH}, \mathrm{JZ}, \mathrm{RQ}, \mathrm{QW}, \mathrm{JQ}$ and MZ contributed to data collection and statistical analysis. SY and ZY contributed to data collection, statistical analysis and manuscript preparation. All authors read and approved the final manuscript.

\section{Ethics approval and consent to participate}

The present study was approved by the Human Ethics Committee of the Affiliated Suzhou Hospital of Nanjing Medical University (approval no. KL901058) and all patients provided written informed consent.

\section{Patient consent for publication}

Patients provide written informed consent for the publication of their data.

\section{Competing interests}

The authors declare that they have no competing interests.

\section{References}

1. Torre LA, Bray F, Siegel RL, Ferlay J, Lortet-Tieulent J and Jemal A: Global cancer statistics, 2012. Ca Cancer J Clin 65: 87-108, 2015.

2. Chen W, Zheng R, Baade PD, Zhang S, Zeng H, Bray F, Jemal A, Yu XQ and He J: Cancer statistics in China, 2015. CA Cancer J Clin 66: 115-132, 2016.

3. Siegel RL, Miller KD and Jemal A: Cancer statistics, 2017. CA Cancer J Clin 67: 7-30, 2017.

4. Kahouli I, Tomaro-Duchesneau $\mathrm{C}$ and Prakash S: Probiotics in colorectal cancer (CRC) with emphasis on mechanisms of action and current perspectives. J Med Microbiol 62: 1107-1123, 2013.

5. Su WB and Liu ZY: MiR-431 inhibits colorectal cancer cell invasion via repressing CUL4B. Eur Rev Med Pharmacol Sci 22: 3047-3052, 2018

6. Goldstein DA, Zeichner SB, Bartnik CM, Neustadter E and Flowers CR: Metastatic colorectal cancer: A systematic review of the value of current therapies. Clin Colorectal Cancer 15: 1-6, 2016.

7. Amaral PP, Dinger ME, Mercer TR and Mattick JS: The eukaryotic genome as an RNA machine. Science 319: 1787-1789, 2008.

8. Guttman M, Amit I, Garber M, French C, Lin MF, Feldser D, Huarte M, Zuk O, Carey BW, Cassady JP, et al: Chromatin signature reveals over a thousand highly conserved large non-coding RNAs in mammals. Nature 458: 223-227, 2009.

9. Nagano $T$ and Fraser P: No-nonsense functions for long noncoding RNAs. Cell 145: 178-181, 2011.

10. Lekka $E$ and Hall J: Noncoding RNAs in disease. FEBS Lett 592: 2884-2900, 2018.

11. Kopp F and Mendell JT: Functional classification and experimental dissection of long noncoding RNAs. Cell 172: 393-407, 2018. 
12. Wang KC and Chang HY: Molecular mechanisms of long noncoding RNAs. Mol Cell 43: 904-914, 2011.

13. Liu Y, Ferguson JF, Xue C, Ballantyne RL, Silverman IM, Gosai SJ, Serfecz J, Morley MP, Gregory BD, Li M and Reilly MP: Tissue-specific RNA-Seq in human evoked inflammation identifies blood and adipose LincRNA signatures of cardiometabolic diseases. Arterioscler Thromb Vasc Biol 34: 902-912, 2014.

14. Liu YW, Sun M, Xia R, Zhang EB, Liu XH, Zhang ZH, Xu TP, De W, Liu BR and Wang ZX: LincHOTAIR epigenetically silences miR34a by binding to PRC2 to promote the epithelial-to-mesenchymal transition in human gastric cancer. Cell Death Dis 6: e1802, 2015.

15. Chang S, Chen B, Wang X, Wu K and Sun Y: Long non-coding RNA XIST regulates PTEN expression by sponging miR-181a and promotes hepatocellular carcinoma progression. BMC Cancer 17: 248, 2017

16. Lu W, Zhang H, Niu Y, Wu Y, Sun W, Li H, Kong J, Ding K, Shen $\mathrm{HM}, \mathrm{Wu} \mathrm{H}$, et al: Long non-coding RNA linc00673 regulated non-small cell lung cancer proliferation, migration, invasion and epithelial mesenchymal transition by sponging miR-150-5p. Mol Cancer 16: 118, 2017.

17. Zheng J, Huang X, Tan W, Yu D, Du Z, Chang J, Wei L, Han Y, Wang C, Che X, et al: Pancreatic cancer risk variant in LINC00673 creates a miR-1231 binding site and interferes with PTPN11 degradation. Nat Genet 48: 747-757, 2016.

18. Sha M, Lin M, Wang J, Ye J, Xu J, Xu N and Huang J: Long non-coding RNA MIAT promotes gastric cancer growth and metastasis through regulation of miR-141/DDX5 pathway. J Exp Clin Cancer Res 37: 58, 2018.

19. Lu Z, Li Y, Wang J, Che Y, Sun S, Huang J, Chen Z and He J: Long non-coding RNA NKILA inhibits migration and invasion of non-small cell lung cancer via NF- $\mathrm{B} /$ Snail pathway. J Exp Clin Cancer Res 36: 54, 2017.

20. Nissan A, Stojadinovic A, Mitrani-Rosenbaum S, Halle D, Grinbaum R, Roistacher M, Bochem A, Dayanc BE, Ritter G, Gomceli I, et al: Colon cancer associated transcript-1: A novel RNA expressed in malignant and pre-malignant human tissues. Int J Cancer 130: 1598-1606, 2012.

21. Ye Z, Zhou M, Tian B, Wu B and Li J: Expression of lncRNA-CCAT1, E-cadherin and N-cadherin in colorectal cancer and its clinical significance. Int J Clin Exp Med 8: 3707-3715, 2015

22. Xiang JF, Yin QF, Chen T, Zhang Y, Zhang XO, Wu Z, Zhang S, Wang HB, Ge J, Lu X, et al: Human colorectal cancer-specific CCAT1-L lncRNA regulates long-range chromatin interactions at the MYC locus. Cell Res 24: 513-531, 2014.

23. Alaiyan B, Ilyayev N, Stojadinovic A, Izadjoo M, Roistacher M, Pavlov V, Tzivin V, Halle D, Pan H, Trink B, et al: Differential expression of colon cancer associated transcript1 (CCAT1) along the colonic adenoma-carcinoma sequence. BMC Cancer 13: 196, 2013.

24. Yang F, Xue X, Bi J, Zheng L, Zhi K, Gu Y and Fang G: Long noncoding RNA CCAT1, which could be activated by c-Myc, promotes the progression of gastric carcinoma. J Cancer Res Clin Oncol 139: 437-445, 2013.

25. Gao Y, Sun L, Wu Z, Xuan C, Zhang J, You Y and Chen X: miR218 inhibits the proliferation of human glioma cells through downregulation of Yin Yang 1. Mol Med Rep 17: 1926-1932, 2018.

26. Cong R, Tao K, Fu P, Lou L, Zhu Y, Chen S, Cai X and Mao L: MicroRNA218 promotes prostaglandin E2 to inhibit osteogenic differentiation in synovial mesenchymal stem cells by targeting 15-hydroxyprostaglandin dehydrogenase [NAD(+)]. Mol Med Rep 16: 9347-9354, 2017

27. Guan B, Wu K, Zeng J, Xu S, Mu L, Gao Y, Wang K, Ma Z, Tian J, Shi Q, et al: Tumor-suppressive microRNA-218 inhibits tumor angiogenesis via targeting the mTOR component RICTOR in prostate cancer. Oncotarget 8: 8162-8172, 2017.

28. Livak KJ and Schmittgen TD: Analysis of relative gene expression data using real-time quantitative PCR and the 2(-Delta Delta C(T)) method. Methods 25: 402-408, 2001.
29. He X, Tan X, Wang X, Jin H, Liu L, Ma L, Yu H and Fan Z: c-Myc-activated long noncoding RNA CCAT1 promotes colon cancer cell proliferation and invasion. Tumour Biol 35: 12181-12188, 2014

30. Liang WC, Ren JL, Wong CW, Chan SO, Waye MM, Fu WM and Zhang JF: LncRNA-NEF antagonized epithelial to mesenchymal transition and cancer metastasis via cis-regulating FOXA2 and inactivating Wnt/ $\beta$-catenin signaling. Oncogene 37: 1445-1456, 2018.

31. Wang ZY, Hu M, Dai MH, Xiong J, Zhang S, Wu HJ, Zhang SS and Gong ZJ: Upregulation of the long non-coding RNA AFAP1-AS1 affects the proliferation, invasion and survival of tongue squamous cell carcinoma via the Wnt $/ \beta$-catenin signaling pathway. Mol Cancer 17: 3, 2018.

32. Huang Y, Zhang J, Hou L, Wang G, Liu H, Zhang R, Chen X and Zhu J: LncRNA AK023391 promotes tumorigenesis and invasion of gastric cancer through activation of the PI3K/Akt signaling pathway. J Exp Clin Cancer Res 36: 194, 2017.

33. Yang Y, Junjie P, Sanjun C and Ma Y: Long non-coding RNAs in colorectal cancer: Progression and future directions. J Cancer 8 : 3212-3225, 2017.

34. Jiang X, Li Q, Zhang S, Song C and Zheng P: Long noncoding RNA GIHCG induces cancer progression and chemoresistance and indicates poor prognosis in colorectal cancer. Onco Targets Ther 12: 1059-1070, 2019

35. Shi L, Hong X, Ba L, He X, Xiong Y, Ding Q, Yang S and Peng G: Long non-coding RNA ZNFX1-AS1 promotes the tumor progression and metastasis of colorectal cancer by acting as a competing endogenous RNA of miR-144 to regulate EZH2 expression. Cell Death Dis 10: 150, 2019.

36. Yu Y, Nangia-Makker P, Farhana L and Majumdar APN: A novel mechanism of IncRNA and miRNA interaction: CCAT2 regulates miR-145 expression by suppressing its maturation process in colon cancer cells. Mol Cancer 16: 155, 2017.

37. Zhang J, Jiang Y, Zhu J, Wu T, Ma J, Du C, Chen S, Li T, Han J and Wang X: Overexpression of long non-coding RNA colon cancer-associated transcript 2 is associated with advanced tumor progression and poor prognosis in patients with colorectal cancer. Oncol Lett 14: 6907-6914, 2017.

38. Zhu L, Tu H, Liang Y and Tang D: MiR-218 produces anti-tumor effects on cervical cancer cells in vitro. World J Surg Oncol 16: 204, 2018

39. Xuan C, Jin M, Gao Y, Xu S, Wang L, Wang Y, Han R and An Q: miR-218 suppresses the proliferation of osteosarcoma through downregulation of E2F2. Oncol Lett 17: 571-577, 2019.

40. Zhang G, He X, Ren C, Lin J and Wang Q: Long noncoding RNA PCA3 regulates prostate cancer through sponging miR-218-5p and modulating high mobility group box 1 . J Cell Physiol 234: 13097-13109, 2019.

41. Warren RS, Yuan H, Matli MR, Gillett NA and Ferrara N: Regulation by vascular endothelial growth factor of human colon cancer tumorigenesis in a mouse model of experimental liver metastasis. J Clin Invest 95: 1789-1797, 1995.

42. Zhang D, Qiu X, Li J, Zheng S, Li L and Zhao H: TGF- $\beta$ secreted by tumor-associated macrophages promotes proliferation and invasion of colorectal cancer via miR-34a-VEGF axis. Cell Cycle 17: 2766-2778, 2018.

43. Schiffmann LM, Fritsch M, Gebauer F, Günther SD, Stair NR, Seeger JM, Thangarajah F, Dieplinger G, Bludau M, Alakus H, et al: Tumour-infiltrating neutrophils counteract anti-VEGF therapy in metastatic colorectal cancer. Br J Cancer 120: 69-78, 2019.

44. Yang T, Zhai H, Yan R, Zhou Z, Gao L and Wang L: IncRNA CCAT1 promotes cell proliferation, migration, and invasion by down-regulation of miR-143 in FTC-133 thyroid carcinoma cell line. Braz J Med Biol Res 51: e7046, 2018.

This work is licensed under a Creative Commons Attribution-NonCommercial-NoDerivatives 4.0 International (CC BY-NC-ND 4.0) License. 